DOI: 10.2478/RAE-2019-0008 Review of Artistic Education no. 172019 69-76

\title{
8. ANALYST VS PERFORMER. THE IMPORTANCE OF STUDYING THE MUSIC ANALYSIS DISCIPLINE FOR THE DEVELOPMENT OF CRITICAL-ANALYTICAL THINKING OF PERFOMER STUDENTS
}

Gabriela Vlahopol ${ }^{19}$

\begin{abstract}
In the music higher education, the appearance of a concept of incompatibility between the performance practice and the students' theoretical and analytical training is a phenomenon with multiple consequences on their training, on the way of organizing a curriculum and a hierarchical deformed attitude on the different subjects in the curriculum.This study summarizes some of the arguments that emphasize the role played by the study of the Music Analysis in developing the musician's ability to understand music from the perspective of the compositional conception, to discover its importance as a stage in the formation of an original performance concept while highlighting the advantages of a collaborative approach between the two areas of training of the musician.
\end{abstract}

Key words: musical analysis, performance, teaching methods

\section{Introduction}

"Players should understand what they play". Donald Francis Tovey's words, found in one of his studies dating back to the first half of the 20th Century are a reflection of the researchers' concerns up to the current times, with regard to the issues of the relation between understanding a musical work form an analytical perspective, and the quality of its playing. The discussion related to the relation musical analysis / performance increased with the evolution in the musicology field, but also due to the appearance of some branching of psychology, such as educational psychology and in particular music psychology (that includes research areas such as Perception and Cognition, Neuropsychology, Cognitive musicology, Music education, Music performance), that focused on the study of the connections between the theoretical and practical areas withing the educational process.

The theoreticians' opinions evolved along time, from the ideology of a direct conditioning of playing by the act and result of an opus analysis (thus raising controversies regarding the role of the instrument player during the performance process) to the quest for a balance, an area where the two fields can meet. In the beginning of the 20th Century (1920-1930), Heinrich Schenker and Hugo Riemann declaimed that music performance should be analytically oriented. In time, this was the basis of a negative attitude towards the theoretical field and its implications on performance: "Performance directions are fundamentally

\footnotetext{
19 Lecturer PhD., “George Enescu” National University of Arts, Iași, Romania, email: gabrielavlahopol@gmail.com
} 
superfluous, since the composition itself express everything that is necessary...performance must come from within the work; the work must breathe form its own lungs - from the linear progressions, neighbouring tones, modulations...About these, naturally, there cannot exist different interpretations." (Heinrich Schenker quoted in Howell, 1992, p. 697)

Moreover, Bowen underlined that "for the last theree hundred years, composers have increasingly tried to exercise more control over the variability of performance by being more specific in everything from pitch content and instrumentation to dynamics and even the physical experience of playing." (Bowen, 1993, p. 140) Thus, many composers like Leonard Bernstein, Igor Stravinski and Arnold Schönberg fostered the idea of the supremacy of creation upon performance, and Schönberg issued one of the toughest statements on the usefulness of a musician's existence: "The performer, for all his intolerable arrogance, is totally unnecessary except as his interpretations make the music understandable to an audience unfortunate enough not to be able to read it in print." (quoted in Cook, 2001, p. 1) In a synthesis of the abovementioned theories, Cook notices the changes in the general acceptance on music as a phenomenon with numerous negative side effects: "In short, we seem to have forgotten that music is a performance art at all, and more than that, we seem to have conceptualized it in such a way that we could hardly think of it that way even if we wanted to." (Cook, 2001, p. 4)

One of the most important titles dedicated to the importance of dialogue between music analysis and performance belongs to Wallace Barry, Musical Structure and Performance (1989); at that time it offered no only arguments to support the relevance of analysis in the performance process, but it also provided solutions for the switching from theory to practice. Moreover, Eugene Narmour, in his study called On the Relationship of Analytical Theory to Performance and Interpretation (1988), conjures numerous negative consequences that may result from lacking deep understanding of the musical text, revealed in particular at the level of the artistic concept on the work and the depth of the message conveyed to the listener. Many studies of authors like Tim Howell (1992), William Rothstein (1995), Joel Lester (1995, 1998), Nicholas Cook (1999, 2001),Vicky Ward (2004, 2007), Lawrence Rosenwald (1993) follow the same direction of congruency of final purposes - understanding the muscial phenomenon, musical communication and solving the issues related to these two processes.

\section{Music analysis from the performer's point of view. Opinions and justifications}

"For most performing musicians, analytical theory is largely a study of the grammar of music. As a utilitarian subject, analysis - wheter of melody, harmony, rhythm, couterpoint, or musical form - presumably makes it possible for performers to learn the various languages of musical styles, thereby 
increasing the liklihood of their producing an informed and aesthetically satisfying intepretation." (Narmour, 1988, p. 317) The concept of musical analysis as a critical instrument, capable of providing and validating a "correct" performance, contributed to the appearance of a well-documented breach between the two areas (Dunsby, 1995; Lester, 1995). Two factors can be identified in this process of separation between the two disciplines, and whose interaction proved to be decisive in time.

- The attitude of higher education teachers and, by default, of their students towards Music analysis

In a survey performed among instrument teachers, elements like structure design, theory, and musical analysis were consistently ranked among the least important aspects of the performance and in the teaching practice of an instrument (Ward, 2004). Instrument teachers are in the ideal position to support the fundamental importance of the structure in understanding a musical score in a practical way. However, although the Music Analysis discipline offers all the necessary means for the future performers to notice and understand the structural elements of music, they face a marginalization attitude, being considered too "academic", unrelated to performance (Aiello\&Williamon, 2002). The chasm between these two areas risks to overturn the fundamental concept of education, that of experimental learning, a principle that underlines the importance of connecting the theoretical knowledge with practical action.

An important factor in increasing the gap between the two areas was the anchoring of teachers in the traditional methods of teaching the instrument, which favors the monopoly of the educator and limits the active participation of the student. Teacher's tendency to focus on elements of subjective, personaltechnical nature, imagination, instinct, sound quality - excludes the simultaneous introduction of a rational, objective aspect represented by musical analysis. The same above quoted study performed by Ward on instrument teachers (Ward, 2004) demonstrated that, despite the openness to linking music analysis with performance, teachers did not have means to integrate theory into practice, separating analysis from its own performance, and at the same time failing to achieve the connection between expression and structure.

Another aspect of the issue is the level at which the discourse between the two areas is projected. Through the studies and research on the topic, the theoreticians address especially the academic area, most of the time including only researchers or top performers, leaving aside instrument teachers, those who have a fundamental role in changing the optics on the relationship between analysis and interpretation among students. Thus, the failure to transmit an appropriate attitude in this respect among instrument teachers directly resulted in similar attitudes in students, which most of the times take on the views of their educators. As a result, instrumental students have developed over time a reaction to reject the idea of "linking analysis to performance, considering the analytical act as a factor that can remove pleasure from the performance experience, 
suggesting that after detailed explanations, the work becomes boring". (Vaughan, 2002, p. 264 quoted in Ward, 2007, p. 1)

- Contribution of theoreticians (musicologists) to creating inaccessible language and expression, inappropriate for performers

The development of the field of musicology in the last half of the 20th century and the first half of the $21 \mathrm{st}$ century led to a diversification of methods of analytical approach, to their modernization until their get closer to scientific research techniques, as well as to a specific grammar of each species. The phenomenon had important consequences in the intersection of the analytical sphere with the interpretative area: the focus of theoreticians on the discovery of hidden structures or the less obvious constructive aspects (the frequent use of a type of agreement) neglecting or avoiding those obvious aspects but rarely capturing the interpreters' attention (related to the theme, the relationship between the sound content of some sections); developing a complicated, tangential or inaccessible analytical language: "terminology is a decisive factor in teachers' perceived negativity towards music analysis." (Ward, 2004). The separation between theoreticians and interpreters is due not only to the language and presentation of musicological studies, but also to their irrelevancy due to the avoidance of analyzes regarding the performance options (versions) of the works and the focus on the theories related to the compositional process.

\section{Music analysis and musical awareness}

Most of the times, in music analysis, the starting point is the score, observed at the abstract level, analyzed in detail using strict analytical methods. Narmour (1988, p. 697) argues that "the study of music theory should enable performers to determine not only how they fit into some stylistic scheme of history but should also endow performers with the means do discover how different intepretations alter the listener's pereption and understanding of living works of art". In the same sense, Howell emphasizes the need for a wider vision on musical analysis, which should be seen as a means of achieving a goal and not a final goal in itself, and the aspects of the analytical process must represent ways to complement and complete the interpretative study.

In an effort to alleviate the inaccessibility of musical analysis or analytical language among students and instrument teachers, Howell suggests to focus on the musical awareness concept. According to Guidlhall School of Music and Drama Woodwind Syllabus, musical awareness "includes the ability to shape phrases, a sense of musical coherence, an understanding of overall structure, sensitivity to the relationship between parts within a texture and an ability to capture mood and character" (Guildhall School of Music and Drama, 2002, p. 217). Olson defined the concept as being fundamental for understanding music's deep meaning: "Awareness is more than listening. Awareness must be approached as a specific condition of human experience which involves feeling, analyzing, and judging. (...) Musical awareness exist at three levels: 1) musical 
details, 2) associations and mental images, and 3) accentuation. The more these three levels are explored, the closer one comes to a definition of aesthetic experience." (Olson, 1984, p. 31)

Starting from the description of the elements that include the musical awareness expression we can find as many elements of correspondence with the field of music analysis. Awareness of the musical phenomenon by discovering the details and their mental association with sound pictures and corresponding states, a cognitive and affective understanding of music at the same time, is the ultimate goal for the training of a student playing an instrument.This is done on an accessible level, familiar to instrument teachers, and in which collaborative teaching can be developed between them and the educators in the theoretical fields.

\section{The role of Music analysis subject in musical training of performing students. Developed skills}

- Sensing the rhythmic models and structures, their circulation on the part of the work and the way it relates to the melodic factor;

- Noticing the melodic details - discovering the main motives of the work, their processing and transformation into the different sections of the work, sensing the connection between different segments based on the melodic correlations;

- Developing harmonic sense, understanding the option for certain modulations, harmonic relationships, tonal correlations between sections;

- Developing the ability of phrasing by understanding the principles underlying the concept of musical phrase: musical sense, cadence principle, constructive principles specific to each stylistic age, understanding the principle of the evolution of a musical idea (beginning, development, climax, solving, conclusion), elements that determine the identity of a musical phrase or a section (melody, rhythm, harmony, writing) etc .;

- Developing a critical thinking and observation of a work, understanding the principles of composition construction, general dramaturgy, with its key moments: expository, developer, conclusive; understanding the correlations between the sections and their psychological role;

- Understanding and capturing the state and character of a work;

- Memorising capacity (Aiello and Williamon, 2002)

- Understanding the work as a whole, not just the line or voice they are playing. Understanding the function of each plan, the role of each instrument / participant in the discourse, the relationship between the soloist and accompaniment and its changes during the work;

- Internal representation of music;

- Coherence of interpretation;

- Forming a personal interpretative concept on the work, without taking it over from others: the choice of dynamics, tempo, culminations, accents, digitization, positions etc. 
There has been a growing concern among students about the degree of uniformity of the performance style. Often, their appeal to recordings of top performers is avoided precisely because of the same phenomenon of the similarity of interpretative options of a particular opus. The interaction between music analysis as instrumental training and interpretation theory can facilitate the young generation a discipline of mixing the expertise of the two domains, which can develop not only the discovery and assumption of unique personal interpretations, but also a discovery of one's own artistic personality.

- Awareness of the composer - performer - listener path. Narmour (1988) states that the temporal materialization of a musical work is not due exclusively to the composer or performer, but to a relationship of interdependence between the creator, the interpreter, and the listener. The role of the performer in this triangle of music completion is to give life to a seemingly schematic score based on graphical conventions and approximations of the composer's intentions, passing it through a process of transformation according to his own aesthetic convictions, stylistic experiences and artistic performance traditions. Consequently, the interpreter must pay special attention not only to the deeper understanding of the composer's intentions, but also he must adapt the message of the work to auditor's sensitivity, aesthetic and stylistic experience.

It is especially important for the auditor not to be directly exposed to the analytical thinking behind the instrument player's conception about performance. The analysis should be just one of the factors of influence in the creation of the interpretative vision without becoming its main foundation.

- Understanding the psychological effect that music has on the listener;

- Achieving a balance between aural perception and analytical perception in the formation of an own interpretative concept. Howell (1992) argues the importance of linking the two types of perceptions, thus eliminating the mechanical studying, instinct-based but lacking depth, from the students' practice. "From the perspective of aural perception (the ability to hear all the details of a piece) and that of analytical perception (the ability to relate those details to a whole), the act of mechanical practice is counterproductive, preventing the ear from working properly to separate these sounds and the mind from assimilating significance. The value of aural perception and analytical understanding in the memorization of a piece is clearly accepted; more problematic, but of equal value, is their relevance to formation of an individual interpretation." (Howell, 1992, p. 699)

- Understanding the expressive structure of the work;

- Noticing details and the ability to link details to the whole. The analysis gives the performer the ability to discover details in the musical score and relate these details to the whole; it develops his critical vision and ability to raise various issues and questions and find viable solutions to them. 


\section{Conclusions. Possible solutions for accessing the Music Analysis field}

Insisting on the role that musical analysis should play in the musician's training, Howell asserts that the analytical study undoubtedly has an educational role.However, when it becomes irrelevant due to the distraction of the interpreter's attention from the music itself, it may become counter-educative (diseducational) (Howell, 1992, p. 702) Also, analysis must be seen as a process and not as a product (Howell, 1992, p. 702). The search for those analytical elements that may be useful to the performer is a fundamental part of the Music Analysis discipline. Analysis and performance must be carried out as simultaneous and interactive processes, not successively (Cook, 1999). In the process of teaching the instrument, musical analysis can help teachers develop more than the psychomotor and interpretative capacities of students by facilitating their complex exercise of the role of educator by implementing general principles of education such as the development of musical thinking. Also, instrument teachers can radically influence the theoretical learning by experimenting in practice, by encouraging students to explore analytical details through interpretation, thus achieving the crucial link between experimentation and learning.

One of the tools offered by instrument teachers to facilitate the relationship between Music Analysis and the study of the instrument is to change the teaching concept. Instrument teachers showed a tendency to concentrate, during teaching, on personal subjective elements: imagination, technique, instinct, elements which, in the absence of an individual analytical investigation, can lead to an unconscious (or conscious) option of performance, a reflection of an existing performance. Teachers' tendency to hold the monopoly within the instrument classes falls in the same traditional view of the act of teaching. Including analytical discussions can increase students' involvement in the educational process, leading to greater autonomy in expressing and adopting their own interpretative options.

An important factor in enhancing the role that Musical Analysis plays in the training of performing students is the change of the teachers' perspective on this field.Research has shown the teachers' tendency to have a negative opinion on musical analysis (Ward 2005), considering it irrelevant, which explains the difficulty with which they integrate the analysis into the instrument teaching process. "One solution on this issue might be to focus our collaborative efforts on how we teach performance rather than how we teach analysis. Specifically, I will suggest theat one way of moving towards this position is to chart developement of an analytically based teaching resources." (Ward, 2007, p. 1) "Performing students must understand every act that precedes the interpretative phenomenon as part of a complex analytical process. Performers may not realize that their choice of fingering or bowing are "analytic", but in the sense that those choices affect the projection of structure, they carry the same interpretative import as analytic notations." (Lester, 1998, p. 2) 
The main way to blur the apparent discrepancy between musical analysis and interpretation is to adopt a different view of the discipline, cancelling its seemingly prescriptive role and emphasizing its semantic creativity and versatility in the interpretative process. "Analysis is something which happens whenever one attends intelligently to the world."(Meyer, 1973, p. 29)

\section{References}

1. Aiello, R., Williamon, A. (2002). Memory. In R. Parncutt, \&G.McPherson (Eds.), The Science and psychology of music performance:Creative strategies for teaching and learning (167-181). Oxford:Oxford University Press

2. Bowen J.A. (1993). The History of Remembered Innovation: Tradition and its Role in the Relationship between Musical Works and Their Performances. The Journal of Musicology, 11(2), 139-173

3. Bowen, J.A. (1996). Performance Practice Versus Performance Analysis: Why Should Performers Study Performance, Performance Practice Review, 9(1), DOI: 10.5642/perfpr.199609.01.03

4. Cook, N. (1999). Analysing Performance and Performing Analysis, in Cook, N., \& Everist, M. (1999). Rethinking Music, Oxford: Oxford University Press, 239-261

5. Cook, N. (2001). Product or Process? Music and Performance, Music Theory Online 7 (http://www.mtosmt.org/issues/mto.01.7.2/toc.7.2.html)

6. Dunsby, J. (1995). Performing Music: Shared Concerns, Clarendon Press, Oxford

7. Howell, T. (1992), Analysis and Performance: The Search for a Middleground, in Paynter, J. (ed.), Companion to Contemporary Musical Thought, London: Routledge

8. Lester, J. (1995). Performance and analysis: interaction and interpretation in Rink, J. (ed.) The Practice of Performance: Studies in Musical Interpretation, Cambridge University Press, 187-216

9. Lester, J. (1998). How theorists relate to musicians, Music Theory Online, 4(2)

10. Narmour, E., \& Solie, R. (1988). On the Relationship of Analytical Theory to Performance and Interpretation, in Meyer, L.B., Narmour, E., \& Solie, R. (Eds.) Explorations in Music, the Arts, and Ideas: Essays in Honor of Leonard B. Meyer, Pendragon Press, Hillsdale, New York

11. Rosenwald, L. (1993). Theory, Text-Setting, and Performance, The Journal of Musicology, 11(1), University of California Press, 52-65

12. Rothstein, W. (1995), Analysis and the Act of Performance in Rink, J. (ed.) The Practice of Performance: Studies in Musical Interpretation, Cambridge University Press, 217-240.

13. Tovey, D.F. (1931). Companion to Beethoven's Pianoforte Sonatas, London: Associated Board of the Royal School fo Music

14. Ward, V. (2007). Teaching Musical Awareness: The development and application of a 'toolkit' of strategies for instrumental teachers, British Journal of Music Education, 24(01), 21-36, DOI: 10.1017/S0265051706007200

15. Ward, V. (2004). The performance teacher as music analyst: a case study, International Journal of Music Education, 22(3), 248-265, DOI: $10.1177 / 0255761404047406$ 